\title{
Posicionamento de mercado das principais marcas nacionais de guitarra pela percepção dos clientes: uma análise multidimensional
}

\author{
Josiel Fernandes de Oliveira \\ Instituto Federal do Sudeste de Minas Gerais \\ (IF Sudeste MG - Campus Rio Pomba) \\ (josieladm2013@hotmail.com) \\ Rafael de Oliveira Mota \\ Instituto Federal do Sudeste de Minas Gerais \\ (IF Sudeste MG - Campus Rio Pomba \\ (rfl.mota@hotmail.com) \\ Edivaldo de Paula Vinha \\ Instituto Federal do Sudeste de Minas Gerais \\ (IF Sudeste MG - Campus Rio Pomba \\ (edivaldordfnet@hotmail.com) \\ Tharcisio Alexandrino Caldeira \\ Instituto Federal do Sudeste de Minas Gerais \\ (IF Sudeste MG - Campus Rio Pomba \\ (tharcisio.caldeira@ifsudestemg.edu.br)
}

Resumo: Tendo em vista o crescimento das marcas nacionais e a elevação das exigências do mercado consumidor de guitarras, o presente artigo buscou investigar como os consumidores posicionam as principais marcas de guitarra nacionais (Condor, Dolphin, Eagle, Giannini, Memphis, Michael, Seizi, Tagima e Vogga). Os dados foram coletados tendo por base uma amostra de 32 alunos/clientes da Live Musical da cidade de Juiz de Fora (MG), buscando conhecer sua preferência entre as marcas de guitarras nacionais. Para isso, foi utilizada a técnica de Escalonamento Multidimensional (EMD), objetivando a construção de um mapa perceptual de duas dimensões. Três lojistas, considerados especialistas em instrumentos musicais, contribuíram com a interpretação do mapa perceptual. Os resultados indicaram que os consumidores avaliaram a preferência das guitarras baseados, principalmente, na relação preço/qualidade e na credibilidade e grau de reconhecimento das marcas analisadas. Neste sentido, as marcas Tagima, Seizi e Michael se destacaram na avaliação dos consumidores, ao passo que a marca Vogga se destacou negativamente na referida avaliação. As marcas envolvidas que se mostraram distantes das preferências dos consumidores podem se basear nesses resultados para reestruturarem seus produtos, tendo por base as estratégias adotadas por Tagima, Seizi e Michael.

Palavras-chave: Posicionamento de mercado; Guitarras nacionais; Escalonamento Multidimensional.

\section{Market positioning of the main domestic guitar makers from customer`s point of view: a multidimensional analyses}

Abstract: Given the growth of domestic brands and the increase of demands from guitar consumers, this article tried to investigate how consumers rate the main domestic guitar makers (Condor, Dolphin, Eagle, Giannini, Memphis, Michael, Seizi, Tagima and Vogga). The data were collected based on a sample of 32 students/clients from Live Musical, from Juiz de Fora, in the state of Minas Gerais, trying to understand their preferences among the brands of national guitars. In order to achieve this, a technique called Multidimensional Scaling (MDS) was used, with the objective of building a two dimensional perceptual map. Three shopkeepers, considered specialists in musical instruments, contributed to the interpretation of the perceptual map. The results indicated that the consumers evaluated their guitar preferences based mainly on the price/quality ratio and on how credible and well- 
known the analysed brands were. As such, the brands Tagima, Seizi and Michael stood out in the assessment of the consumers, whereas Vogga was negatively evaluated in the referred evaluation. The involved brands which were distant from consumer preferences can can rely on these results to restructure their products, based on the strategies adopted by Tagima, Seizi and Michael.

Keywords: market positioning; domestic guitar; Multidimensional Scaling.

\section{INTRODUÇÃO}

A inserção da guitarra elétrica no cenário musical brasileiro, de acordo com Visconti (2010), foi marcada por certa resistência da parte dos músicos. Uma das justificativas apontadas pelo autor refere-se ao medo de alguns quanto a perda da identidade nacionalista, visto que o instrumento era visto como um símbolo norteamericano - fruto do esforço das empresas Fender e Gibson. Outra justificativa era baseada no receio de que o som produzido pela guitarra não fosse autêntico, devido ao fato de que seu funcionamento consiste na utilização de componentes elétricos.

Contudo, atualmente o instrumento é amplamente difundido e muito aplicado na música nacional. De acordo com Caraveo (2016), a aceitação por parte do público se deu graças aos movimentos da MPB, principalmente na chamada "época de ouro" das rádios, bem como devido à disseminação de movimentos advindos do rock.

Nesse contexto, surgiram as primeiras fabricantes nacionais de guitarras elétricas. Inicialmente com qualidade inferior, as guitarras nacionais atualmente apresentam atributos expressivos e satisfatórios, aliados ao preço mais acessível se comparado com produtos importados. Tendo em vista o crescimento dessas empresas no mercado brasileiro, pode-se observar também um acirramento da concorrência e, dentro dessa atual conjuntura, aparece a necessidade de que essas empresas voltem a atenção para os clientes, de modo a suprirem mais adequadamente suas necessidades e expectativas.

Portanto, é preciso que cada empresa/marca busque se posicionar na mente do consumidor promovendo os atributos que diferenciam seus instrumentos dos oferecidos pelos concorrentes, fazendo com que isso seja tão familiar ao cliente que este, ao se deparar com um conjunto de atributos desejados, se lembre de determinada marca que lhe atende por completo e que, na sua percepção, esteja involuntariamente ligada as características que marcam seu desejo ou necessidade. Conforme Martins (2006) já adverte, o consumidor começa a formar um grupo 
composto por duas ou três marcas para cada produto e tende a concentrar suas escolhas entre elas, a fim de reduzir o tempo dispensado à tomada de decisão.

Diante do exposto, a presente pesquisa buscou investigar como os consumidores posicionam as principais fabricantes nacionais de guitarras. Para tanto, inicialmente a pesquisa procurou identificar tais fabricantes para, a partir daí, verificar como os consumidores posicionam tais empresas no tocante à sua preferência pelas guitarras.

Assim, este trabalho tem o intuito de contribuir com mais informações sobre o setor para empresários e lojistas que, por meio desta pesquisa, poderão visualizar o mercado e assim estabelecer melhores estratégias para alcançar novos consumidores, além de garantir melhor atendimento ao público que já possuem entregando maior confiança, detalhes e valor.

Além disso, o estudo forneceu um cenário aos consumidores para uma melhor compreensão das marcas, pois demonstra um panorama das marcas em conjunto, dando um parecer de como estas são posicionadas segundo a percepção dos consumidores e o diferencial que as posiciona.

Por fim, a presente pesquisa também pode contribuir com estudos ligados à formulação de estratégias de marketing ligadas ao posicionamento de mercado, uma vez que, após verificações em diversas bases de periódicos nacionais - como Spell, SciElo e Google Acadêmico - não foram encontrados na literatura brasileira estudos aplicados ao setor de instrumentos musicais.

\section{REFERENCIAL TEÓRICO}

Dentre as várias ferramentas típicas da área de marketing, cabe destacar o processo de segmentação do mercado consumidor, a escolha do mercado alvo e das ações que visam posicionar as ofertas das organizações para os mercados que se pretende atender. Tais ferramentas são de grande importância por permitirem conhecer de modo mais profundo as características e anseios dos consumidores para melhor atendê-los. Após sua aplicação, torna-se mais fácil para a organização desenvolver a parte tática de sua estratégia (o mix de marketing). 


\subsection{Segmentação}

Por mais que se pretenda atender o maior número de clientes possível, é necessário que as empresas compreendam que é praticamente impossível atender a todos. "Na selva de comunicação que existe lá fora, a única esperança de marcar altos pontos é ser seletivo, concentrar-se em metas bem definidas, praticar a segmentação" (RIES; TROUT, 2009). Portanto, as organizações devem segmentar seus clientes de modo a dividi-los em grupos característicos e, assim, escolher um (ou alguns) destes grupos como seu público-alvo e concentrar seus esforços, visando responder devidamente aos anseios dos consumidores de forma lucrativa e benéfica para ambos.

Ikeda, Campomar e Pereira (2008, p. 26) mencionam que:

A evolução dos mercados e das empresas, cuja produção em massa e atendimento generalizado dos mercados passam a oferecer cada vez mais ofertas diferenciadas para mercados restritos, traz à tona a importância de uma boa segmentação de mercado. (IKEDA; CAMPOMAR; PEREIRA, 2008, p. 26)

Para segmentar um mercado, é necessário conhecer quem é o consumidor, suas peculiaridades, personalidade e a influência que estas exercem na aquisição de bens e utilização de serviços. Tais informações possibilitam que a empresa identifique qual produto oferecer para os grupos mais dispostos a adquiri-lo (BARBOSA; DIAS; WALCHHUTTER, 2015).

Há uma diversidade de critérios a partir dos quais se pode segmentar um mercado e, embora cada um deles tenha potencial para revelar importantes informações para a empresa, a combinação deles, apesar de mais trabalhosa, produz resultados mais abrangentes e robustos em termos de caracterização dos segmentos (ROCHA; FERREIRA; SILVA, 2012). O Quadro 01 apresenta os principais critérios utilizados no processo de segmentação de mercado:

Quadro 1: Critérios utilizados para segmentação de mercado.

\begin{tabular}{|l|l|}
\hline \multicolumn{1}{|c|}{ Critério } & \multicolumn{1}{c|}{ Aspectos considerados no critério } \\
\hline Geográfico & Regiões, clima, dimensões e densidade populacional \\
\hline Demográfico & Ocupação, gênero, faixa etária, etc. \\
\hline Comportamental & Aspectos do comportamento de compra, uso e consumo. \\
\hline Psicográfico & Estilo de vida, personalidade, valores \\
\hline Por produto & Produtos novos ou usados, produtos padrões ou customizados \\
\hline Por sensibilidade a preço & Reação a níveis e mudanças de preço \\
\hline
\end{tabular}

Fonte: Elaborado pelos autores com base em Rocha, Ferreira e Silva (2012). 
Após a segmentação, é necessário que a empresa escolha os segmentos em que atuará. Assim, estará determinando seu mercado-alvo, ou seja, o público para o qual concentrará seus esforços, desenvolvendo um composto de marketing pensado exclusivamente para aquele grupo (TAVARES; AFONSO; LOCATELLI, 2011).

\section{2 identificação do público alvo}

Rocha e Christensen (2008) afirmam que a escolha do público-alvo consiste no passo final da segmentação, ou seja, momento que a empresa deve fazer uma análise estratégica dos segmentos encontrados de modo a avaliar a conveniência de atuar em um ou alguns deles, levando sempre em consideração a quantidade e o tamanho do segmento a ser atendido. Para que isso ocorra, os referidos autores citam que há três questões importantes que a organização deve se lembrar no momento de definir seu público-alvo, sendo elas: i) qual o tamanho dos segmentos?; ii) segmentos desse tamanho permitem que a empresa atue de maneira estratégica?; iii) a empresa deve atuar em quantos segmentos?

O público-alvo é constituído por um ou mais segmentos que apresenta $(\mathrm{m})$ melhores condições de atendimento por parte da empresa (VEIGA-NETO, 2007). Porém, é necessário que a empresa avalie esse grupo para descobrir se é economicamente viável atendê-lo, considerando por exemplo que custo ela terá para desenvolver estratégias (mídias, canais, força de vendas) de acesso a esse conjunto de compradores e se esse grupo oferece segurança para empresa em termos de concorrência, ou seja, se a atuação da empresa não lhe deixa vulnerável a ataques externos (ROCHA; CHRISTENSEN, 2008).

Após definir o público-alvo e a respectiva estratégia de cobertura de mercado (que pode ser ampla, estreita ou intermediária), um importante passo é desenvolver propostas de posicionamento competitivo, tendo em mente, entretanto, que o consumidor, ao desenvolver sua percepção e opinião quanto às ações, produtos e a empresa como um todo, é quem de fato posicionará uma empresa (RIES; TROUT, 2009). 


\subsection{Posicionamento de mercado}

De acordo com Ries e Trout (2009), a ideia de posicionamento surgiu da necessidade de amenizar a situação em que se encontrava o consumidor, que comumente era bombardeado por um excessivo volume de informações advindo do meio publicitário. Tais informações, por vezes, não obtinham o efeito desejado ou até geravam resultados contrários ao planejado.

Nesse sentido, Moreira (2006) explicou que o consumo é fortemente influenciado pela visão criada pelo cliente a respeito de determinados produtos e que quando as empresas se deram conta disso, começaram "a derramar uma enxurrada de mensagens e anúncios de diversas formas", no intuito de impor uma imagem de seus produtos que devia ser aceita a qualquer custo. Na intenção de contornar toda essa poluição causada por uma sociedade extremamente comunicativa, o posicionamento se fundamentou de modo crucial em simplificar a mensagem a ser transmitida ao cliente. Assim, buscava criar, alterar ou promover imagens específicas sobre as marcas (LEE, et al., 2018).

O posicionamento do produto consiste nos atributos importantes que o cliente percebe e utiliza para definir o produto. Sarquis e lkeda (2007) afirmam que o posicionamento é a forma como o consumidor realmente percebe a imagem da empresa e a posiciona em sua mente, quando associada aos concorrentes.

Considerando que são os clientes quem verdadeiramente definem o valor de um produto ou serviço, cada vez mais se torna necessário que as organizações atuem de modo a buscar uma diferenciação eficiente, que as posicionem em um ponto estratégico na percepção dos clientes, de forma a influenciar as escolhas destes (KRAWCZYK; XIANG, 2016). Gouvêa e Niño (2010) relacionam a diferenciação às características expressivas que repassam uma percepção de valor ao consumidor, diferenciando a oferta da empresa perante suas concorrentes.

Para tanto, é necessário que as empresas criem e fortaleçam suas marcas de maneira a obter êxito no seu processo de diferenciação. A decisão de compra dos consumidores, assim como a percepção de qualidade, é influenciada fortemente pela imagem da marca ou produto que a organização procura transmitir, que nem sempre condiz com o que o cliente enxerga (SARQUIS; IKEDA, 2007).

Essa diferenciação, segundo Ries e Trout (2009), é alcançada por meio do posicionamento, técnica definida por eles como sendo a visão e aceitação da real 
percepção que os clientes têm do produto ou serviço, a qual servirá de ponto de partida dos trabalhos para renovar essas percepções com intuito de alcançar uma nova posição desejada em face do potencial consumidor.

Posicionamento é o que a empresa faz com a mente do seu público-alvo e não com o produto em si. Por mais que possa existir a necessidade de se aplicar algumas mudanças, como embalagem, preço e até nome, estas não passam de "mudanças cosméticas", que não são consideradas como reais mudanças no produto, mas sim, pequenos ajustes com propósito de obter uma preciosa posição na mente dos potenciais clientes (RIES; TROUT, 2009).

Alfinito e Torres (2012) explicam que o produto, apesar de ter importantes características, não é o que há de mais representativo em uma oferta para o cliente, pois importa mais o significado que o cliente percebe a respeito do produto em questão, e segundo os referidos autores, esse significado normalmente é criado a partir de estímulos externos. Portanto, muitas vezes as empresas se veem com problemas para promover seus produtos por não enxergarem essa realidade e não aplicarem ações adequadas à situação vivenciada. Atualmente, é necessário que as empresas concentrem seus esforços nas percepções de seus potenciais clientes, buscando soluções na mente de seus consumidores e não apenas ou necessariamente no produto (RIES; TROUT, 2009).

Já que o posicionamento consiste em se alojar de modo positivo na mente do potencial cliente, é necessário descobrir um espaço nela que a organização possa dominar. Segundo Ries e Trout (2009), o modo mais fácil de se fazer percebido pelo cliente e entrar em sua mente é sendo o primeiro a chegar, pois assim, o produto encontrará um espaço vazio para poder explorar e disseminar suas características.

Rocha, Ferreira e Silva (2012) indicam algumas possíveis alternativas de posicionamento a serem perseguidas por diferentes empresas, como apelar para a singularidade, proveniência, grupo-alvo, experiência, sucessão, etc.

Cabe ressaltar, entretanto, que buscar uma posição sem saber onde se está atualmente é uma atitude equivocada, de modo que é fundamental descobrir onde a marca está posicionada na mente do cliente, bem como com que concorrente ela está relacionada para que, somente a partir de tais informações, a empresa possa traçar planos de reposicionamento, quando for o caso.

Diante disso, diversas pesquisas procuram conhecer o posicionamento de diferentes empresas a fim de contribuírem com o avanço do conhecimento em setores 
específicos, bem como com as estratégias organizacionais. Krawczyk e Xiang (2016), por exemplo, investigaram o posicionamento de empresas do setor hoteleiro. Claveria e Poluzzi (2017), por sua vez, pesquisaram o posicionamento dos principais destinos turísticos do mundo. Sondhi (2017) posicionou os consumidores de alimentos orgânicos em um mapa cujos eixos revelavam preocupações ambientais e com a saúde e Lee, Kim e Won (2018) investigaram o posicionamento de marcas de produtos esportivos.

Vários fatores influenciam os clientes e fazem com que eles posicionem determinada marca de acordo com suas percepções. Entretanto, quais fatores são usados, quantos, se foram considerados isoladamente ou não, são informações que mudam de cliente para cliente e é muito provável que talvez nem o próprio consumidor consiga distinguir exatamente quais foram, devido ao fato de serem avaliações extremamente intrínsecas. Considerando que muitas das avaliações dos consumidores são bastante subjetivas e, consequentemente, difíceis de serem compreendidas, a proposição de um mapa perceptual emerge como uma alternativa promissora no sentido de compreender o posicionamento que os consumidores atribuem a produtos ou marcas, tanto em termos de similaridade quanto de preferência (BORTOLI; BIRCK, 2017).

De acordo com Moreira (2006), os mapas perceptuais normalmente são estruturados com finalidades exploratórias, no intuito de conhecer que lugar determinados produtos ocupam na mente do consumidor e quanto este valoriza o produto/serviço e, a partir daí, tal conhecimento adquirido embasa o planejamento estratégico de marketing, permitindo designar um posicionamento objetivo a ser usado pela empresa. Portanto, um mapa perceptual pode ser entendido como um mapa de posicionamento, afinal, ele demonstra a posição aproximada que determinado produto ocupa na mente do cliente.

De acordo como Peter e Olson (2009, p. 384), um mapa de posicionamento "é uma representação visual da percepção dos consumidores sobre produtos, marcas ou modelos concorrentes".

Mapas perceptuais (ou de posicionamento) podem ser construídos partindo de qualquer informação sobre o produto ou de um ou mais produtos dos concorrentes em um mesmo mercado (MOREIRA, 2006; BORTOLI; BIRCK, 2017), cabendo, entretanto, explorar os consumidores a respeito dos atributos dos produtos pesquisados (SONDHI, 2017). 
Segundo Peter e Olson (2009), o mapa de posicionamento, além de informar a respeito do espaço ocupado na mente do cliente, bem como o valor que lhe é atribuído, ainda é capaz de fornecer dados que propõem bases para a formação de estratégias de posicionamento e reposicionamento no caso de uma batalha por espaço na mente já saturada dos clientes potenciais.

De acordo com Hair Jr. et al. (2009), mapas de posicionamento são representações geométricas de percepção de indivíduos, referentes a questões de similaridade e preferência. Sendo assim, essas são representadas em um espaço multidimensional buscando possibilitar aos indivíduos inferir sobre determinado posicionamento de um objeto referente a outro objeto, a partir das dimensões obtidas com o mapa de posicionamento.

Concluindo, o cliente é quem reafirmará se está de acordo ou não com a proposta de posicionamento de uma marca e ele o faz quando vincula determinadas características (boas ou ruins) a determinadas marcas, produtos ou empresas em geral. Assim, cabe às empresas desenvolverem propostas de posicionamento que de fato correspondam ao que a empresa pretende transmitir e, sobretudo, importa que as empresas façam com que todos os elementos do composto de marketing guardem estreita relação com o posicionamento pretendido. Isso porque se a empresa não oferecer subsídios para que os consumidores posicionem sua marca da maneira como ela gostaria, o consumidor a posicionará por conta própria, podendo ou não tal percepção ser o que a marca espera.

\section{METODOLOGIA}

Uma vez que o presente estudo buscou compreender melhor como as marcas de guitarras nacionais estão sendo posicionadas no mercado e suas inter-relações de concorrência por meio da ótica do consumidor, pode-se afirmar que finalidade da presente pesquisa foi exploratória. Quanto aos meios de investigação, sua classificação é de campo. 


\subsection{População e amostragem}

Marconi e Lakatos (2010) definem população como um conjunto formado por seres que apresentam ao menos uma característica em comum, seres esses que podem ser animados ou não. Em geral, quando os dados são tratados de forma estatística, existem determinados critérios quanto ao tamanho da amostra que devem ser respeitados. Contudo, o método utilizado nesta pesquisa - Escalonamento Multidimensional (EMD) - não demanda um tamanho pré-determinado de amostra pois, de acordo com Hair Jr. et al. (2009), o referido método apresenta-se como uma técnica exploratória que não emprega uma variável estatística e, portanto, não depende do tamanho da amostra para suas análises.

Diante disto, a presente pesquisa considera como população todos os consumidores de instrumentos musicais. Desta população, foi retirada uma amostra por conveniência, composta por 32 estudantes da escola de música Live Musical, de Juiz de Fora, que se voluntariaram a participar da pesquisa. A amostragem por conveniência, de acordo com Herdeiro (2012), se relaciona com a escolha pessoal dos pesquisadores ou relacionada a alguma característica desejada pelos mesmos, em relação aos respondentes.

A escolha por estudantes de música - em especial, estudantes de guitarra - se deu em função destes estarem em constante contato com diversas marcas e modelos de guitarras, em busca de encontrar a melhor combinação de equipamentos que aprimorem sua performance. Tais características os transformam em potenciais formadores de opinião.

Por sua vez, a escolha pela escola de música Live Musical se deu em função desta concentrar espacialmente uma grande quantidade do público-alvo pretendido. A referida escola atua no mercado há mais de 17 anos, com qualidade reconhecida no setor, o que contribui para encontrar potenciais respondentes com maior capacidade de comparação e discernimento para responder ao questionário.

\subsection{Coleta dos dados}

Os dados foram coletados por meio da aplicação de questionários, elaborados de acordo com os critérios estabelecidos por Malhotra (2012) e Herdeiro (2012), que 
mencionam a necessidade de que estes devem fornecer dados que esclareçam a visão dos respondentes (amostra) a respeito do objeto de estudo.

Foi aplicado um questionário estruturado impresso aos respondentes, solicitando que estes indicassem sua preferência em relação às principais marcas de guitarras nacionais, entre os meses de maio e junho de 2017. Os dados foram coletados por meio de uma escala ordinal, na qual Malhotra (2012) explica que o respondente deve definir notas entre 01 (mais preferido) a 09 (menos preferido) para as marcas que foram objeto da presente pesquisa.

Para a definição das principais marcas nacionais de guitarras, a pesquisa utilizou-se da validação por juízes. Três especialistas do ramo de varejo de instrumentos musicais da Zonta da Mata Mineira foram selecionados, em função do notório saber, para auxiliar na definição das principais marcas: Condor, Dolphin, Eagle, Giannini, Memphis, Michael, Seizi, Tagima e Vogga.

\subsection{Tratamento dos dados}

Os dados foram analisados por meio do método de Escalonamento Multidimensional (EMD) que, segundo Hair Jr. et al. (2009, p. 484), é um "procedimento que permite determinar a imagem relativa percebida de um conjunto de objetos", com o objetivo de "transformar os julgamentos dos consumidores em distâncias representadas em espaço multidimensional". Diante da escassez de trabalhos sobre posicionamento de mercado direcionados para o setor de instrumentos musicais, o referido método se apresentou como o mais adequado, possibilitando formulações e levantamentos de questões para nortear estudos futuros.

O EMD busca, por meio de procedimentos matemáticos (sem inferência estatística), fornecer um mapa cujo objetivo é revelar justamente a estrutura "oculta" formada pela percepção dos consumidores (HERDEIRO, 2012).

Malhotra (2012) afirma que, após a definição do problema de pesquisa e da coleta de dados, o EMD passa ainda por quatro etapas até a conclusão da análise dos dados, a saber: i) seleção do procedimento de EMD (métrico x não métrico, nível agregado $\mathrm{x}$ individual); ii) decisão quanto ao número de dimensões (duas $\mathrm{x}$ três dimensões); iii) rotulação e interpretação das dimensões; e iv) avaliação de confiabilidade e validade do modelo. 
Neste sentido, a presente pesquisa procedeu com o EMD não métrico (a partir de dados ordinais), construindo um mapa perceptual de nível agregado e de duas dimensões, com base nos dados de preferência. Hair Jr. et al. (2009) indicam que esse modelo é definido como um modelo de análise interna, que consiste em obter o mapa perceptual utilizando somente dados de preferência para calcular os pontos ideias e as distâncias (posições) entre as marcas no mapa.

Após a rotulação e interpretação das dimensões, as mesmas foram validadas por meio de consultas aos mesmos especialistas que foram consultados na fase inicial da pesquisa.

Por fim, o mapa perceptual necessita ser avaliado quanto à confiabilidade e à validade de seus resultados. Malhotra (2012) aponta que o índice de stress-l de Kruskal é um bom indicador de qualidade, posto que mede a pobreza do ajuste dos dados em relação ao modelo de EMD. Nesse sentido, o autor indica que valores superiores a 0,2 representam um ajuste dos dados considerado pobre, ao passo que valores inferiores a 0,025 são considerados excelentes.

\section{RESULTADOS E DISCUSSÕES}

O modelo EMD baseado nos dados de preferência apresentou índices de ajuste bastante satisfatórios - com stress-I de Kruskal igual a 0,020, o que permitiu o avanço da análise dos dados. O mapa perceptual obtido pode ser visto na Figura 1:

Figura 1: Mapa perceptual das marcas de guitarras nacionais com pontos ideais.

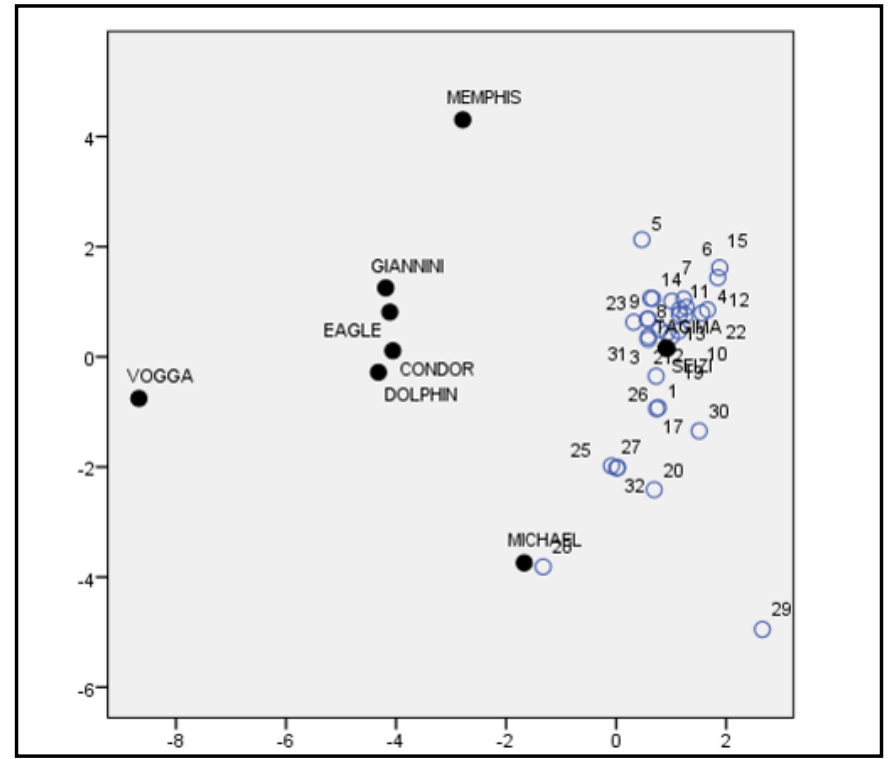

Fonte: Autores 
No referido mapa perceptual, percebe-se que os pontos ideais dos respondentes - os pequenos círculos numerados e de cor clara - se concentram em torno de um mesmo espaço do mapa, permitindo evidenciar que as marcas Michael, Seizi e Tagima são as que mais se aproximam do ideal destes consumidores, de acordo com os atributos utilizados pelos mesmos para a comparação das guitarras.

No que diz respeito à interpretação destes atributos e tentativa de classificá-los em duas dimensões, este processo se deu por meio de análise qualitativa dos instrumentos analisados e após consulta aos especialistas do ramo de instrumentos musicais. Como resultado, foi possível inferir que uma das dimensões se refere à relação preço/qualidade das guitarras nacionais, ao passo que a outra dimensão diz respeito à credibilidade e ao grau de reconhecimento das marcas, conforme pode ser visto na Figura 2.

Figura 2: Mapa perceptual das marcas de guitarras nacionais, com pontos ideais.

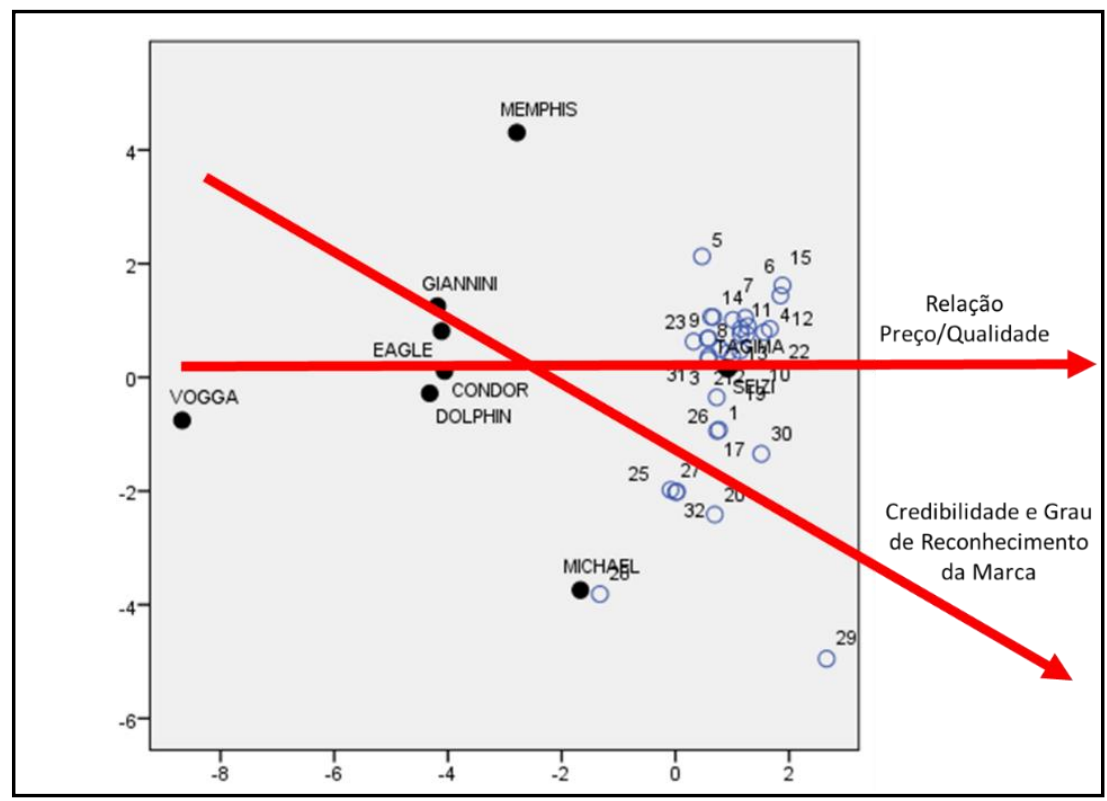

Fonte: Dados da Pesquisa.

No que diz respeito à dimensão "preço/qualidade", foi possível identificar que a marca Vogga é classificada como uma marca que oferece opções de "menos por menos". Posicionada no extremo esquerdo do eixo, ela se apresenta oferecendo instrumentos de baixo preço, porém com qualidade desproporcionalmente inferior ao mesmo.

$\mathrm{Na}$ outra extremidade do eixo, pode-se afirmar que as marcas Tagima e Seizi foram classificadas pelos respondentes como as que possuem maior qualidade. Isto é comprovado pelo fato delas ocuparem justamente as posições onde situam-se as 
preferências (pontos ideais) dos consumidores. Vale ressaltar que essas marcas possuem um preço mais elevado, porém, tal preço é justificado pela qualidade superior.

Por sua vez, a dimensão relacionada à credibilidade e grau de reconhecimento da marca indicam as marcas Tagima e Seizi como marcas posicionadas com mais credibilidade por parte do consumidor. Esse fator pode ter levado em consideração aspectos como maior investimento em marketing por parte dessas marcas e também por patrocinarem vários músicos importantes que contribuem com uma forte imagem para o cenário musical brasileiro, levando em consideração a guitarra. As guitarras dessas duas marcas também se diferenciam por se voltarem a um público mais exigente, que quer um instrumento nacional que tenha credibilidade no mercado.

A marca Michael também se destaca, logo após as marcas Tagima e Seizi, e é posicionada no mercado como marca que possui também uma forte credibilidade e reconhecimento por parte dos consumidores, por ser uma marca com reconhecimentos não só no setor de guitarras, mas em contrapartida, atuar em outros setores de instrumentos como baterias, violões, instrumentos de sopro, entre outros.

No extremo oposto, tem-se a marca Vogga, detentora de menor credibilidade e reconhecimento por parte dos consumidores devido ao fato de ser uma marca nova do mercado e ainda produzir instrumentos que são mais propensos a iniciantes no mercado de guitarra.

É possível identificar que os resultados da pesquisa permitem a elaboração de estratégias de marketing amparadas pela percepção dos clientes em relação a seus produtos. Por exemplo, a empresa responsável pela guitarra Vogga podem elaborar estratégias visando o consumo de seus instrumentos por iniciantes (simbolizando a primeira guitarra de sua vida, por exemplo), ao passo que Tagima e Michael podem elaborar estratégias baseadas na confiabilidade da marca e dos produtos, já conhecidos no mercado. A adoção de estratégias diferenciadas é condizente com a sugestão de Ries e Trout (2009), no sentido de diferenciar positivamente em uma posição na mente dos potenciais clientes.

Por outro lado, as empresas responsáveis pelas guitarras Giannini, Eagle, Condor e Dolphin encontrarão dificuldades para se diferenciarem umas das outras, no que tange à singularidade proposta por Rocha, Ferreira e Silva (2012). Isto porque estas guitarras ocupam o mesmo espaço no mapa perceptual dos potenciais clientes entrevistados. Nesse sentido, tais empresas deverão buscar estratégias que 
ressaltem aspectos diferentes dos observados no mapa perceptual fruto desta pesquisa e, assim, buscar um local exclusivo na mente dos consumidores.

Percebe-se que, observando os critérios utilizados na definição do mapa perceptual que, enquanto a Vogga deve ocupar um espaço reservado a músicos iniciantes, Tagima, Seizi e Michael ocupam um espaço consolidado como referência no mercado de guitarras nacionais. Por fim, as demais marcas são percebidas como instrumentos intermediários, demandando investimento adicional na busca por atributos que possam aproximá-las das marcas líderes de preferência.

\section{CONSIDERAÇÕES FINAIS}

Esta pesquisa se propôs a investigar como os consumidores posicionam as principais marcas de guitarras nacionais no mercado. Esse objetivo foi cumprido por meio de uma análise de preferência que resultou em um mapa perceptual, obtido por meio do Escalonamento Multidimensional (EMD).

A análise do mapa perceptual indicou que os consumidores definiram suas preferências, em termos de guitarras nacionais, baseados na percepção da relação entre preço e qualidade, bem como na percepção da credibilidade e de reconhecimento da marca.

No que tange à relação entre preço e qualidade, a marca Vogga foi posicionada como uma marca que possui preço e qualidade inferiores as concorrentes de acordo com os consumidores. Já no outro extremo, as marcas Tagima e Seizi foram consideradas como marcas com preço mais elevado, tendo em consideração que também possuem uma qualidade maior em relação às demais.

Por sua vez, a dimensão referente à credibilidade e reconhecimento da marca indica que as marcas Tagima e Seizi foram posicionadas como marcas com maior credibilidade e reconhecimento por parte dos consumidores, tendo em vista que essas marcas podem ter maiores investimentos em marketing. Já a marca Michael também apresenta um bom posicionamento de credibilidade e reconhecimento pelos consumidores, em decorrência de atuar também na fabricação de outros tipos de instrumentos musicais. No outro extremo, a marca Vogga ainda apresenta uma baixa credibilidade e reconhecimento de marca, evidenciado por ser aparentemente nova no mercado e produzir instrumentos voltados ao público iniciante. 
Os resultados indicam, portanto, uma separação entre um instrumento para iniciantes (Vogga) e instrumentos considerados referência do mercado nacional (Tagima, Seizi e Michael). Os demais instrumentos encontram-se posicionados em um bloco intermediário, de forma que as empresas responsáveis por estas marcas necessitam decidir se é seu objetivo a manutenção de suas marcas em uma posição intermediária ou a diferenciação de seus produtos em direção a um dos dois setores mais perceptíveis no mercado - iniciantes ou referência (liderança).

Assim, é possível concluir que as empresas devem dispensar maior atenção à questão do posicionamento de mercado por parte dos clientes, desenvolvendo e agregando cada vez mais atributos, buscando aprimorar a qualidade nos produtos.

Em relação às limitações observadas no decorrer do trabalho, destaca-se o fato do método de EMD não permitir a generalização de resultados, sendo necessárias pesquisas futuras de caráter mais quantitativo, a fim de permitir tal generalização.

Esta pesquisa futura poderia, por exemplo, estender sua coleta de dados a outras escolas de música e outros ambientes em que se estudam ou se compartilham informações voltadas a instrumentos musicais, mais especificamente guitarras. Isso poderia ampliar o conhecimento nesta área, possibilitando um detalhamento maior do setor de instrumentos musicais. Por fim, uma pesquisa mais abrangente e que se aprofunde qualitativamente, também permitiria interpretações mais precisas das dimensões envolvidas.

\section{REFERÊNCIAS}

ALFINITO, S.; TORRES, C. V. Modelo de influência cultural no consumo: uma proposta baseada em axiomas sociais. RAM - Revista Administração Mackenzie, São Paulo, v. 13, n. 5, p. 15-38, Out. 2012.

BARBOSA, A. S.; DIAS, M. R.; WALCHHUTTER, S. Segmentação de mercado: análise de artigos sobre segmentação psicográfica. Administração de Empresas em Revista, v. 14, n. 15, p. 96-100, 2015.

BORTOLI, L. V.; BIRCK, A. Mapa perceptual no contexto empresarial: aspectos relevantes para a sua elaboração. Revista de Administração IMED. vol. 7, n. 1, p. 230-249, 2017.

CARAVEO, S. C. Uma breve história da guitarra elétrica: a conquista acadêmica no Brasil. Boa Vista, 2016. IX Encontro Regional Norte da Abem. UFPR. Pará. Disponível em: http://www.abemeducacaomusical.com.br/conferencias/index.php/ixencontroregnt/reg_ norte2016/paper/viewFile/1562/741 >; Acesso em: 05 de abril. 2017. 
CLAVERIA, O.; POLUZZI, A. Positioning and clustering of the world's top tourist destinations by means of dimensionality reduction techniques for categorical data. Journal of Destination Marketing \& Management. v. 6. p. 22-32, 2018.

DOMINGUEZ, S. V. O valor percebido como elemento estratégico para obter a lealdade dos clientes. Caderno de Pesquisas em Administração. São Paulo, 2000. V.7, n.4, 53-64, out-dez 2000.

GOUVÊA, M.A.; NIÑO, F.M. A diferenciação no processo de posicionamento de marketing e o setor de turismo. Gestão \& Regionalidade, São Caetano do Sul, v.26, n. 76, 4-16, 2010.

HAIR JR., J. F; BLACK, W. C; BABIN, B. J; ANDERSON, R. E.; TATHAM, R. L. Análise multivariada de dados. 6. ed. Porto Alegre: Bookman, 2009.

HERDEIRO, R. F. C. Escalonamento Multidimensional. In: CORRAR, L. J; PAULO, E; DIAS FILHO, J. M. (Coord.). Análise Multivariada: para cursos de Administração, Ciências Contábeis e Economia. São Paulo: Atlas, 2012.

IKEDA, A. A; CAMPOMAR, M. C; PEREIRA, B. C. S. O uso de coortes em segmentação de marketing. Organizações e Sociedade. Salvador, v. 15, n. 44, p. 25-43, 2008.

KRAWCZYK, M.; XIANG, Z. Perceptual mapping of hotel brands using online reviews: a text analytics approach. Inf Technol Tourism, v. 16, p. 23-43, 2016.

LEE, J.L.; KIM, Y.; WON, J. Sports brand positioning: Positioning congruence and consumer perceptions toward brands. International Journal of Sports Marketing and Sponsorship, 2018.

MALHOTRA, N. K. Pesquisa de marketing: uma orientação aplicada. 6. ed. Porto Alegre: Bookman, 2012.

MARCONI, M. de, A; LAKATOS, Eva M. Fundamentos de metodologia científica. 7 ed. São Paulo: Atlas, 2010.

MARTINS, J.R; Branding: O Manual para Você Criar, Gerenciar e Avaliar Marcas. São Paulo, SP: [s.n.], 2006.

MOREIRA, J. A. da. S. Mapas perceptuais e variações na participação de mercado. 2006. 166f. Dissertação (Mestrado em administração de Empresas) - Fundação Getúlio Vargas Escola de Administração de Empresas de São Paulo, São Paulo, 2006. Disponível em: <http://bibliotecadigital.fgv.br/dspace/bitstream/handle/10438/2267/57859.pdf?sequenc $\mathrm{e}=2 \&$ isAllowed=y $>$. Acesso em: 13 de jun. 2015.

PETER, P. J.; OLSON, J. C. Comportamento do consumidor e estratégia de marketing. 8 ed. São Paulo: Mc Graw-Hill, 2009.

RIES, A. TROUT, J. Posicionamento: A batalha pela sua mente. 1. Ed. São Paulo: M. Books, 2009.

ROCHA, A. CHRISTENSEN, C. Marketing: Teoria e prática no Brasil. 2. ed. São Paulo: Atlas, 2008. 
ROCHA, A.; FERREIRA, J. B.; SILVA, J. F. Administração de marketing: conceitos, estratégias, aplicações. São Paulo: Atlas, 2012.

SARQUIS, A. B.; IKEDA, A. A prática de posicionamento de marca em agências de comunicação. Revista de Negócios, Blumenau, v. 12, n. 4, p. 55-70, out./dez. 2007.

SONDHI, N. Consumption of organic food products: an emerging market perspective Int. J. Management Practice, v. 10, n. 1, p. 30-48, 2017.

TAVARES, M. C.; AFONSO, T.; LOCATELLI, R. L. Segmentação de mercado, diferenciação de produtos e a perspectiva da antropologia do consumo. Revista Gestão \& Tecnologia. Pedro Leopoldo, v. 11, n. 1, p. 106-122, 2011.

VISCONTI, E. L. A guitarra elétrica na música popular brasileira: os estilos dos músicos José Menezes e Olmir Stocker. 2002.Campinas, 2010. Tese (Doutorando em Música). IA/UNICAMP. Campinas, 2010.2 Disponível em: <http://repositorio.unicamp.br/bitstream/REPOSIP/284970/1/Visconti\%2c\%20Eduardo \%20de\%20Lima_D.pdf>; Acesso em: 04 de abr. 2017.

VEIGA-NETO, A. R. Um estudo comparativo de formas de segmentação de mercado: uma comparação entre VALS-2 e segmentação por variáveis demográficas com estudantes universitários. Revista administração contemporânea, Curitiba, v. 11, n. 1, p. 139161, 2007. 